\title{
Kalanchoe Pinnata aqueous extract has the potential to improve haematological profile and fatigue status of mice subjected to Free Swimming Endurance Test
}

Orelien Sylvain Mtopi Bopda 1, ${ }^{*}$, Odine Perez Maloba ${ }^{1}$, Mbigah Pascal Monju ${ }^{1}$, Germain Sotoing Taiwe ${ }^{1}$ and Théophile Dimo ${ }^{2}$ 1 Department of Zoology and Animal Physiology, Faculty of Science, University of Buea, P.O. Box 63, Buea (Cameroon).
2 Department of Animal Biology and Physiology, Faculty of Science, University of Yaoundé I, P.O. Box 812, Yaoundé
(Cameroon).

GSC Biological and Pharmaceutical Sciences, 2021, 17(02), 063-075

Publication history: Received on 30 September 2021; revised on 07 November 2021; accepted on 09 November 2021

Article DOI: https://doi.org/10.30574/gscbps.2021.17.2.0327

\begin{abstract}
Introduction: Kalanchoe pinnata extracts have been shown to possess beneficial cardiovascular effects, analgesic and myorelaxant activities. This study aimed at evaluating the haematological and anti-fatigue effects of its aqueous extract.

Materials and methods: This was an in vivo pharmacological experiment, carried out in the Laboratory of Zoology, University of Buea, from January to May 2018. A total of 48 mice were subjected to a $90 \mathrm{mins} /$ day-free endurance swimming test for 14 days. Two groups of mice received distilled water and $12 \% \mathrm{NaCl}$ solution, respectively. Five groups received the plant extract $(25,50,100$ and $200 \mathrm{mg} / \mathrm{kg} /$ day $)$ and $200 \mathrm{mg} / \mathrm{kg} /$ day $+\mathrm{NaCl}$. One positive control group received $5 \%$ Vitamin C $(1.97 \mathrm{mg} / \mathrm{kg} /$ day $)$. All administrations were by gavage. Maximum swimming time, glycaemia, lactatemia, uremia, triglyceridemia, haematological indices, tissue glutathion peroxidase, malondialdehyde, glucose and creatine kinase-MB in the heart or gastrocnemius muscle were measured.

Results: K. pinnata (50 and $100 \mathrm{mg} / \mathrm{kg} /$ day) induced a non-significant increase of the swimming duration, compared to neutral control. However, the $12 \% \mathrm{NaCl}$ group recorded a significant $(\mathrm{P}<0.05)$ increase. In the blood, $\mathrm{NaCl}$ induced a decrease of platelets that was significantly reverted by the extract in the $200 \mathrm{mg} / \mathrm{kg}+\mathrm{NaCl}$ group. The extract prevented the increase of the level of $\mathrm{CK}-\mathrm{MB}$ in $\mathrm{NaCl}$ group and decreased the serum triglycerides, glucose, urea nitrogen and Lactate levels. In the tissues, MDA and CK-MB levels significantly increased $(\mathrm{P}<0.001)$ in the negative control. These increases were significantly $(\mathrm{P}<0.001)$ prevented by K. pinnata $(200 \mathrm{mg} / \mathrm{kg} /$ day $)$.
\end{abstract}

Conclusions: Significant biochemical variations support the hypothesis that $K$. pinnata could be used to delay exercise induced fatigue.

Keywords: Kalanchoe pinnata; Haematological parameters; Biochemical parameters, Exercise; Anti-fatigue; Mice

\section{Introduction}

Regular exercise is known to help improve health and alleviate cardiovascular diseases, diabetes and even cancer [1]. However, strenuous exercise causes excessive production of reactive oxygen species, lipid peroxides, and lactic acid, which can damage muscle tissues [2]. The determination of exercise tolerance of an animal is done by assessment through physical examination of heart and respiratory rates $[3,4]$, but haematological and biochemical changes may also be strong indicators of endurance [5]. In endurance races, stress and fatigue can be clearly expressed by changes

\footnotetext{
${ }^{*}$ Corresponding author: Orelien Sylvain Mtopi Bopda

Department of Zoology and Animal Physiology, Faculty of Science, University of Buea, P.O. Box 63, Buea (Cameroon). 
in circulating erythrocyte and leucocyte numbers. Tissue remodeling can also occur and this is seen as changes in plasma urea, proteins and Creatine-Kinase (CK) [6]. Furthermore, endurance performances have exhibited elevated muscle enzymes such as CK and Lactate Dehydrogenase [7]. Kalanchoe pinnata has been shown to possess beneficial cardiovascular, analgesic, anti-inflammatory, anti-oxidant and myorelaxant activities [8, 9, 10]. We hypothesized that Kalanchoe pinnata could be used to improve the haematological profile and delay the exhaustion time of exercising mice. This study aimed at evaluating the effects of the aqueous leaf extract of $K$. pinnata on the haematological and fatigue status of mouse.

\section{Material and methods}

\subsection{Plant material and extraction}

Fresh leaves of Kalanchoe pinnata were harvested in Buea (Cameroon), in May 2017 and authenticated at the Limbe Botanical Herbarium, South West Cameroon, where a specimen has been deposited (Voucher Number SCA2770). The material ( $2 \mathrm{~kg}$ ) was pounded by means of porcelain laboratory pounding cup, and then macerated with water (3L) for 24hours. This step was followed by filtration and evaporation in the oven (45으) yielding $59.2 \mathrm{~g}(2.96 \%)$ of dried powder. The stock solution $(1 \mathrm{~g} / \mathrm{mL})$ was prepared by dissolving the above extract in distilled water. The following concentrations of extract were used: $2,4,8$ and $16 \mathrm{mg} / \mathrm{mL}$ respectively for the doses of 25, 50, $100 \mathrm{and} 200 \mathrm{mg} / \mathrm{kg}$. Oral administration of the plant extract was performed using a non-flexible gavage needle with round end, fixed at the extremity of a syringe.

\subsection{Animals rearing and distribution of groups}

Animals were reared in the Animal House of Department of Zoology and Animal Physiology, University of Buea, in plastic cages; under 12 hour-day/night natural cycle and 25ㄷ-temperature. They were carefully handled according to International Guidelines (CIOMS) [11]. Access to feed and water was ad-libitum. The feed was a standard mice chow (National Veterinary Laboratory (LANAVET), Cameroon) composed of carbohydrates (52\%), protein (22\%), fat (6.5\%), water (12\%), fishmeal (6\%), and fiber (4.5\%).

A total of 48 mice were divided randomly into eight groups of six mice each. Group 1, a neutral control, received the vehicle (distilled water) only. Groups 2, 3, 4, 5 received 25, 50, 100 and 200mg/kg, respectively, of $K$. pinnata extract orally daily, for 14 days. Group 6 received only $12 \% \mathrm{NaCl}$ and group 7 was given $12 \% \mathrm{NaCl}$, ten minutes after K. pinnata administration $(200 \mathrm{mg} / \mathrm{kg})$. Group 8 received Vitamin C (50 mg/kg, per os). 12\% NaCl was administered to groups 6 and 7 to promote electrolytic imbalance of the internal environment and eventually cardiovascular dysfunctions [12, $13,14]$.

\subsection{The 90-minute free swimming test}

One hour after the oral administration of mice with the extract, reference solution or the vehicle as described previously [15], each animal was subjected to the 90-minute free swimming training. The tests were repeated from day 1 to day 14. Each animal was placed individually in a swimming bath $(90 \mathrm{~cm}$ length $\times 45 \mathrm{~cm}$ width $\times 45 \mathrm{~cm}$ height $)$, filled with water to a depth of $35 \mathrm{~cm}$ and maintained at $25 \pm 1^{\circ} \mathrm{C}$. The swimming duration was recorded immediately at the exhaustion. Fatigue was determined by failure of coordinated movements and incapacity to return to the surface within $10 \mathrm{sec}$. The mice were then removed from the swimming bath, dried with a paper towel, and returned to their original cages. The bath water was replaced after each session. ${ }^{15}$ One hour after the final dose treatment on day 14 , mice from each group were subjected again to the 90-minutes free swimming test and their performances recorded.

\subsection{Sacrifice of animals and sample collection}

On the $14^{\text {th }}$ day of experiment and about 30 minutes after the last recording, mice were anaesthetized using chloroform $99 \%$. About $3-4 \mathrm{~mL}$ of blood was collected by cardiac puncture using a $5 \mathrm{~mL}$ syringe. Part of the blood collected from each animal in properly labelled 5mL EDTA tubes was shaken gently to allow it homogenize. It was then processed for the analysis of haematological parameters. The remaining blood was collected in dried tube, allowed to rest at room temperature for $40-60 \mathrm{mins}$. It was then centrifuged at $3000 \mathrm{rpm}$ at $4^{\circ} \mathrm{C}$ for $10 \mathrm{mins}$ to obtain serum (stored at $-28^{\circ} \mathrm{C}$ ) for the analysis of biochemical parameters: CK-MB, blood glucose (Glu), triglycerides (TG), blood lactic acid (BLA), and blood urea nitrogen (BUN).

Immediately after blood collection, the mice were decapitated. The heart and hind limb muscle of each mouse was dissected out for biochemical analyses. The heart and right gastrocnemius muscles were cleaned using $0.9 \%$ saline and 
then weighed using a sensitive electronic balance. All tissue samples above were taken and stored frozen at $-28^{\circ} \mathrm{C}$ awaiting homogenates preparation.

\subsection{Haematological analyses}

A blood count was ran using the Full Blood Count machine, URIT 3300 following the manufacturer's instructions, to automatically get the following indices: white blood cells (WBC), monocyte (MON), lymphocyte (LYM), granulocyte (GRA), haematocrit (HCT), red blood cell (RBC), platelet (PLT) and haemoglobin (Hb).

\subsection{Biochemical analyses of the serum}

Serum glycaemia, CK-MB, serum triglyceride, serum lactatemia, and serum urea nitrogen were determined. The serum levels of glucose were evaluated using a glucometer (Accu-Chek Active Meter). The triglyceride and CK-MB concentrations were, by spectrophotometry, measured using a commercial kit for measurement of triglycerides in serum or plasma (CHRONOLAB SYSTEMS, Diputación 260, Spain, 2014 version and Travessia Prat de la Riba, Spain and 2017 Version respectively). Serum lactic acid concentrations were determined using an L-lactate assay kit (Abcam 65331 L-Lactate assay kit). Finally, levels of urea nitrogen were measured using an enzymatic method with Bioassay System, CA Kit (QuantiChrom ${ }^{\mathrm{TM}}$ Urea Assay Kit).

\subsubsection{Determination of Creatine Kinase $-M B$}

The experimental conditions and procedure were respected, as instructed by the manufacturer (Chronolab, Travessia Prat de la Riba, Spain and 2017 Version). The spectrophotometer was set at $340 \mathrm{~nm}$, at room temperature $24-25^{\circ} \mathrm{C}$. A $1 \mathrm{~cm}$ light path cuvette was used. The equipment was adjusted to zero with distilled water. $\mathrm{R}_{1}$, the buffer, contained imidazole at pH 6.7 (100 mmol/L), glucose $(20 \mathrm{mmol} / \mathrm{L})$, magnesium acetate $(10 \mathrm{mmol} / \mathrm{L})$ and EDTA (2 mmol/L). R2 contained an anti CK-MB (2000 U/L), ADP ( $2 \mathrm{mmol} / \mathrm{L})$, AMP ( $5 \mathrm{mmol} / \mathrm{L})$, di-Adenosine-5-pentaphosphate (10 mmol/L), $\mathrm{NADP}^{+}(2 \mathrm{mmol} / \mathrm{L})$, hexoquinase (HK, $\left.2500 \mathrm{U} / \mathrm{L}\right)$, glucose-6-phosphate dehydrogenase (1500 U/L), N-acetyl cysteine $(20 \mathrm{mmol} / \mathrm{L})$ and creatinine phosphate $(30 \mathrm{mmol} / \mathrm{L})$. The two reagents $\left(\mathrm{R}_{1}\right.$ and $\left.\mathrm{R}_{2}\right)$ were mixed and incubated for 10 minutes. The initial absorbance $\left(\mathrm{A}_{1}\right)$ of the sample was recorded and the stopwatch was started. The value was recorded after 5 minutes again $\left(A_{2}\right)$. The difference in the absorbance was then calculated as follows: Change in $A b s o r b a n c e(\Delta A)$ $=$ Final Absorbance $\left(A_{2}\right)$ - Initial Absorbance $\left(A_{1}\right)$.

Conversion: $\Delta \mathrm{A} \times 1651=\mathrm{U} / \mathrm{L}$ CK-MB.

\subsubsection{Determination of Triglyceride}

The kit was used following the CHRONOLAB SYSTEMS manual. The reagent was prepared by strictly following the prescription, then incubated for 5 minutes at $37^{\circ} \mathrm{C}$. The absorbance (A) of the samples was read against the Blank. The calculation was done as follows:

$$
\frac{\text { A)Sample } x \text { Standard concentration }}{A \text { Standard }}=m g / d \text { triglycerides in the sample. }
$$

Conversion: $\mathrm{mg} / \mathrm{dL} \times 0.0113=\mathrm{mmol} / \mathrm{L}$

\subsubsection{Determination of L-lactate}

Similarly to the above, reagents were prepared following the manufacturer's instructions and serum analysed. The concentration of L-lactate in the test samples was calculated as:

Lactate concentration $(\mathrm{nmol} / \mu \mathrm{L})=(L a / S v) * D$

Where: La = amount of Lactic acid in the sample well calculated from standard curve (nmol).

Sv = volume of sample added into the well $(\mu \mathrm{L}) . \mathrm{D}=$ sample dilution factor.

\subsubsection{Determination of Urea Nitrogen}

With regards to Blood Urea Nitrogen (BUN) calculation, reagents and samples were prepared following manufacturer's instructions. After gently mixing, the vials were incubated for $20 \mathrm{~min}$ and Optical Density (OD) read. Calculation of Urea concentration $(\mathrm{mg} / \mathrm{dL})$ of the sample was done as follows: 


$$
[\text { Urea }](\mathrm{mg} / \mathrm{dL})=(\text { ODsample }- \text { ODblank }] /[\text { ODstandard }- \text { ODblank }] \times n \times[\text { Std }]
$$

Where $\mathrm{OD}_{\text {sample }}, \mathrm{OD}_{\text {blank }}$ and $\mathrm{OD}_{\text {standard }}$ are $\mathrm{OD}$ values of sample, blank and standard, respectively. $\mathrm{n}$ is the dilution factor. $[\mathrm{Std}]=50$ (or 5 for low urea samples), urea standard concentration $(\mathrm{mg} / \mathrm{dL}$ ).

Conversion: BUN (mg/dL) = [Urea $] / 2.14$

\subsection{Homogenate preparation and analyses}

The tissues were used to prepare $20 \mathrm{mg}$ tissue/mL homogenate of tissue by homogenizing in phosphate buffer (pH 7.4). The homogenates were centrifuged at $10,000 \mathrm{rpm}$ for $10 \mathrm{~min}$ at $4^{\circ} \mathrm{C}$, and the resulting supernatant was used for the biochemical measurement. From each muscle, $10 \%(\mathrm{w} / \mathrm{v})$ homogenate was prepared with ice-cold $0.1 \mathrm{M}$ phosphate buffer ( $\mathrm{pH}$ 7.4). From the supernatants, glutathione peroxidase (GPx), Malondialdehyde (MDA) and creatine kinase-MB concentrations were assessed. For the glycogen determination, a specific protocol was followed.

\subsubsection{Measurement of glycogen level}

Heart and gastrocnemius muscle glycogen concentrations were measured calorimetrically using anthrone reagent [16]. Briefly, after hydrolysis of the heart and gastrocnemius muscle samples in $30 \% \mathrm{KOH}$ at $100^{\circ} \mathrm{C}$ for $30 \mathrm{~min}$, the preparation was cooled in an ice bath, then $1.5 \mathrm{~mL}$ of $95 \%$ ethanol added to the vials. After centrifugation at $10,000 \mathrm{rpm}$ for $15 \mathrm{~min}$, the supernatants were allowed to descant and the tubes were allowed to drain on a filter paper for $4-5 \mathrm{mins} .0 .5 \mathrm{~mL}$ of distilled water and $1 \mathrm{~mL}$ of $0.2 \%$ anthrone were added, and the vials were placed in a boiling water bath for $20 \mathrm{~min}$. The absorbance of the solution in vials was determined at 620nm using a calorimeter (V-530, Jasco Co., Japan). The level of glycogen is expressed as $\mathrm{mg} / \mathrm{g}$ wet tissue.

\subsubsection{Measurement of glutathione peroxidase level}

Heart and skeletal muscle glutathione Peroxidase (GPx) was measured according to the method of Ellman (1959). An equal quantity of homogenate was mixed with $10 \%$ trichloroacetic acid and centrifuged to separate the proteins. $2 \mathrm{~mL}$ of phosphate buffer ( $\mathrm{pH} 8.4$ ), $0.5 \mathrm{~mL}$ of $5^{\prime} 5$-dithiobis (2-nitrobenzoic acid) and $0.4 \mathrm{~mL}$ of double distilled water were added to $0.01 \mathrm{~mL}$ of this supernatant. The mixture was vortexed and the absorbance read at $412 \mathrm{~nm}$ within $15 \mathrm{~min}$. The concentration of glutathione peroxidase was expressed as $\mu \mathrm{g} / \mathrm{g}$ tissue, using the law of Beer-Lambert: $\varepsilon . C . L ;$ where

$\varepsilon$ : the extinction coefficient $=13600 \mathrm{~mole}^{-1} \cdot \mathrm{cm}^{-1} ; \mathrm{C}$ : the concentration of the sample (in the cuvette); L: light path=1 $\mathrm{cm}$.

\subsubsection{Measurement of malondialdehyde level}

Malondialdehyde (MDA), was measured as described by Liu et al. in 1990. The reagents acetic acid $1.5 \mathrm{~mL}(20 \%, \mathrm{pH} 3.5)$, $1.5 \mathrm{~mL}$ thiobarbituric acid $(0.8 \%)$ and $0.2 \mathrm{~mL}$ sodium dodecyl sulphate $(8.1 \%)$ were added to $0.1 \mathrm{~mL}$ of processed tissue samples, and then heated at $100^{\circ} \mathrm{C}$ for $60 \mathrm{~min}$. The mixture was cooled then $5 \mathrm{~mL}$ of $\mathrm{n}$-butanol/pyridine (15:1) and $1 \mathrm{~mL}$ of distilled water were added. The mixture was vortexed vigorously. After centrifugation at $4000 \mathrm{rpm}$ for $10 \mathrm{~min}$, the organic layer was separated and absorbance was measured at $532 \mathrm{~nm}$ using a spectrophotometer. The concentration of MDA is expressed in $\mathrm{nmol} / \mathrm{g}$ tissue.

$$
[\mathrm{MDA}](\mathrm{mmol} / \mathrm{g} \text { tissu })=\frac{O D \times V t}{\varepsilon \times L \times V i \times m}
$$

Where OD: optical density; Vt: total volume of the medium (cuvette) $(\mathrm{mL})$; Vi: volume of the sample (in the cuvette) $(\mathrm{mL}) ; \mathrm{m}$ : weight of used tissue (g); L: light path $=1 \mathrm{~cm} ; \varepsilon$ : the extinction coefficient $=1,56 \times 10^{5} \mathrm{mmol}^{-1} \cdot \mathrm{cm}^{-1}$.

\subsubsection{Determination of Creatine Kinase - $M B$}

Similarly to serum analysis, the supernatant collected after centrifugation of homogenates was analysed.

\subsection{Statistical analyses}

Data were expressed as mean \pm standard error of the means (S.E.M.) per group. Statistical differences between control and treated groups were tested by one-way analysis of variance (ANOVA), followed by the Tukey's multiple comparison test. The differences were considered significant at $\mathrm{P}<0.05$. The statistical package used for the analysis was GraphPad InStat 3.10 for Window (GraphPad Software, San Diego, CA, USA) and Excel. 


\subsection{List of abbreviations}

- BLA Blood lactic acid

- BUN Blood urea nitrogen

- CAT Catalase

- CK Creatine-Kinase

- Glu Blood glucose

- Glyco Glycogen

- GRA Granulocyte

- GPx Glutathione peroxidase

- GSH glutathione

- $\mathrm{Hb}$ Haemoglobin

- HCT Haematocrit

- Krpinnata Kalanchoe pinnata

- LYM Lymphocyte

- MDA Malondialdehyde

- MON Monocyte

- NC Neutral control

- PLT Platelet

- $\quad$ RBC Red blood cell

- SOD superoxide dismutase

- TG Triglycerides

- WBC White blood cell

\section{Results}

\subsection{Evaluation of total swimming endurance time per group}

Figure 1 below shows the swimming duration in various groups after a 14-day treatment. The effect of $K$. pinnata extract on the swimming duration was not dose-dependent. A non-significant increase of the swimming duration was observed in the groups administered with 50 and $100 \mathrm{mg} / \mathrm{kg} /$ day of the plant extract, compared to neutral control. Group $2(12 \%$ $\mathrm{NaCl})$ recorded a significant $(\mathrm{P}<0.05)$ increase that was not reverted by the extract at the highest dose $(200 \mathrm{mg} / \mathrm{kg}+\mathrm{NaCl})$. The positive control group (Vit C) equally showed a significance increase of the swimming duration $(P<0.05)$, compared to the neutral control

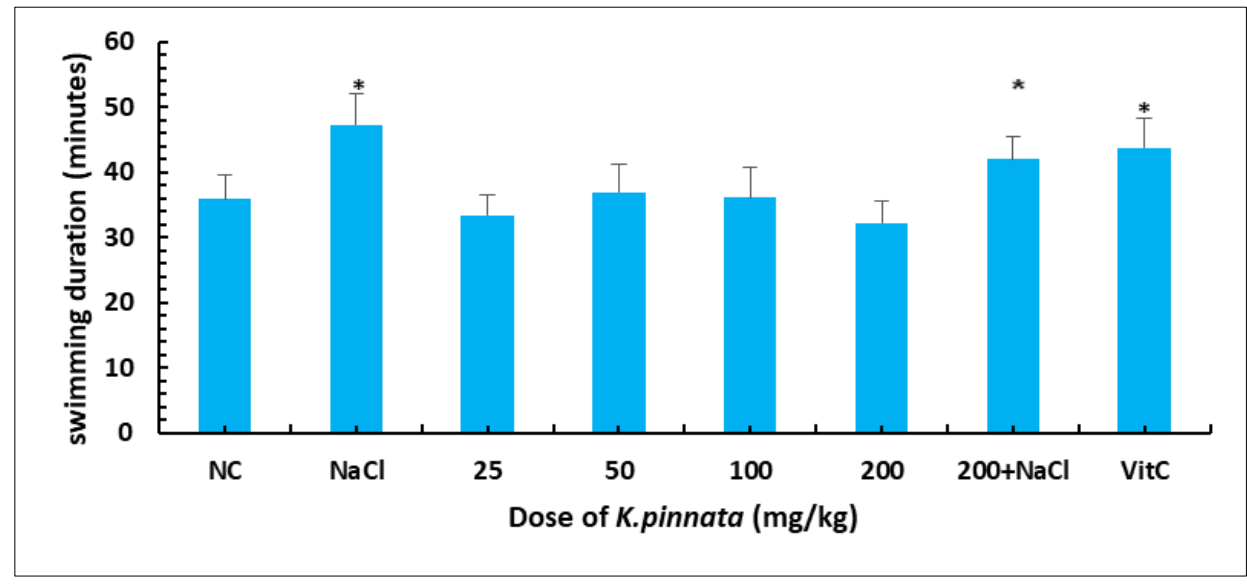

Figure 1 The effects of Kalanchoe pinnata aqueous extract on the swimming duration of mice

Each value represents the mean \pm SEM, $n=6 .{ }^{*} \mathrm{P}<0.05$ (significantly different from NC). NC: neutral control. $\mathrm{NaCl}$ and Vit $\mathrm{C}$ are negative and positive controls, respectively. $200+\mathrm{NaCl}$ group received $K$. pinnata extract $(200 \mathrm{mg} / \mathrm{kg})$ concurrently with $12 \% \mathrm{NaCl}$. 


\subsection{Effects of Kalanchoe pinnata aqueous extract on haematological indices}

The RBC in the treatment groups $50 \mathrm{mg} / \mathrm{kg}$ and $200 \mathrm{mg} / \mathrm{kg}+\mathrm{NaCl}$ were significantly lower than the neutral control group $(\mathrm{P}<0.05, \mathrm{P}<0.01$ respectively). No other significant change was observed with the administration of the extract at the doses 25,100 and $200 \mathrm{mg} / \mathrm{kg} /$ day. Also platelets significantly decreased in the negative control $(\mathrm{NaCl}$ group, $\mathrm{P}<0.01)$ compared to normal control, while this variation was largely reverted in the $200 \mathrm{mg} / \mathrm{kg}+\mathrm{NaCl}(\mathrm{P}<0.001)$. There were no significant differences in the percentage haematocrit and haemoglobin concentrations (Table 1)

\subsection{The effects of Kalanchoe pinnata aqueous extract on leukocytes of mice}

The administration of K. pinnata extract did not cause any significant variation of the levels of WBC, compared to the neutral control group; a non-significant decrease was observed in the negative control ( $\mathrm{NaCl}$ group). However, there was a significant increase $(\mathrm{P}<0.001)$ in the group administered with $200 \mathrm{mg} / \mathrm{kg}+\mathrm{NaCl}$, compared to the $\mathrm{NaCl}$ group. Compared to lymphocytes in the neutral control, all groups showed significant decrease $(\mathrm{P}<0.01)$ (Table 2$)$.

\subsection{The effects of Kalanchoe pinnata aqueous extract on serum biomarkers of fatigue}

Serum glycaemia, CK-MB, triglyceride, lactatemia, and urea nitrogen were determined. Compared to the neutral control group, a significant decrease of the glycaemia was observed in the group treated with $200 \mathrm{mg} / \mathrm{Kg}$ (from $123.50 \pm 9.70$ to $71.76 \pm 0.70 \mathrm{mg} / \mathrm{dL}, \mathrm{P}<0.05)$. A significant increase of the level of CK-MB was observed in animals administered with $\mathrm{NaCl}$, compared to neutral control (from $2.87 \pm 0.24$ to $7.99 \pm 0.155 \mathrm{U} / \mathrm{L}, \mathrm{P}<0.001$ ). When concurrently administered with K. pinnata $(200 \mathrm{mg} / \mathrm{kg}$ ), the plant extract prevented the increase induced by $\mathrm{NaCl}$ alone (from $7.99 \pm 0.16$ to $2.9 \pm 0.23$, $\mathrm{P}<0.001$ ). The level of CK-MB in Vit $\mathrm{C}$ administered animals was comparable to the neutral control and the $200 \mathrm{mg} / \mathrm{kg}+\mathrm{NaCl}$ groups. The plant extract caused a significant $(\mathrm{P}<0.001)$ decrease of the level of triglycerides, compared to neutral control, at all administered doses. However, when administered concurrently with $\mathrm{NaCl}$, there was a significant increase $(\mathrm{P}<0.05)$. Compared to neutral control, a significant decrease of the levels of urea nitrogen and Llactate was observed in all the groups, except $200 \mathrm{mg} / \mathrm{kg}+\mathrm{NaCl}$ (Table 3 ).

\subsection{The effects of Kalanchoe pinnata aqueous extract on biomarkers in heart muscle of mice}

As shown in table 4 , the treatment of animals for two weeks with $K$. pinnata extract $(50-200 \mathrm{mg} / \mathrm{kg} / \mathrm{day})$ had no significant effect on the levels of MDA, GPx and CK-MB in the heart, compared to neutral control. MDA and CK-MB levels in the heart significantly increased $(\mathrm{P}<0.001)$ only in the negative control group treated with $12 \% \mathrm{NaCl}$. These increases were significantly $(\mathrm{P}<0.001)$ prevented by the treatment of animals with $K$. pinnata $(200 \mathrm{mg} / \mathrm{kg} / \mathrm{day})$ in the $200 \mathrm{mg} / \mathrm{kg}+\mathrm{NaCl}$ group. There was no significant difference in glutathione peroxidase levels in any treatment group, when compared to the neutral control $(\mathrm{P}>0.05)$

\subsection{The effects of Kalanchoe pinnata aqueous extract on biochemical markers in gastrocnemius muscle of mice.}

Table 5 shows that in the gastrocnenius muscle, there was a significant increase of the levels of MDA in animal groups treated with $12 \% \mathrm{NaCl}$ and $K$. pinnata at the doses of 25 and $50 \mathrm{mg} / \mathrm{kg} /$ day $(\mathrm{P}<0.0001$ and $\mathrm{P}<0.001$ respectively), compared to neutral control. When compared to $12 \% \mathrm{NaCl}$ group, the MDA in the $200+\mathrm{NaCl}$ group was significantly lower $(\mathrm{P}<0.0001)$.

Glutathion peroxidase levels in the muscles significantly decreased only for the $12 \% \mathrm{NaCl}$ treatment group, compared to the neutral control $(\mathrm{P}<0.01)$. A similar decrease was observed for the level of glucose in all the groups except 50 and $100 \mathrm{mg} / \mathrm{Kg} /$ day 
Table 1 The effects of Kalanchoe pinnata aqueous extract on RBC, platelets, haematocrit and Hb of mice

\begin{tabular}{|c|c|c|c|c|c|c|c|c|}
\hline Animal group & NC & $\mathrm{NaCl}$ & 25 & 50 & 100 & 200 & $200+\mathrm{NaCl}$ & VitC \\
\hline $\operatorname{PLAx} 10^{3} / \mathrm{mm}^{3}$ & $569.40 \pm 6.1$ & $519.57 \pm 10.82^{* *}$ & $585 \pm 10.35$ & $606.34 \pm 9.0$ & $604.24 \pm 8.8$ & $577.58 \pm 8.2$ & $589.11 \pm 5.25^{d}$ & $574.28 \pm 4.8$ \\
\hline $\mathrm{Hb}(\mathrm{g} / \mathrm{dL})$ & $10.52 \pm 0.06$ & $10.75 \pm 0.25$ & $10.70 \pm 0.1$ & $10.62 \pm 0.05$ & $10.88 \pm 0.16$ & $10.73 \pm 0.19$ & $10.61 \pm 0.07$ & $10.58 \pm 0.04$ \\
\hline $\mathrm{RBC} \times 10^{6} / \mathrm{mm}^{3}$ & $5.75 \pm 0.08$ & $5.45 \pm 0.11$ & $5.42 \pm 0.10$ & $5.28 \pm 0.05^{*}$ & $5.38 \pm 0.12$ & $5.37 \pm 0.09$ & $5.23 \pm 0.03^{* *}$ & $5.38 \pm 0.12$ \\
\hline HCT (\%) & $27.74 \pm 0.62$ & $28.41 \pm 0.42$ & $28.82 \pm 0.3$ & $28.03 \pm 0.71$ & $27.30 \pm 0.53$ & $28.35 \pm 0.49$ & $28.83 \pm 0.38$ & $28.29 \pm 0.49$ \\
\hline
\end{tabular}

Each value represents the mean $\pm \mathrm{SEM}, \mathrm{n}=6 .{ }^{*} \mathrm{P}<0.05,{ }^{* *} \mathrm{P}<0.01$ (significantly different from neutral control group). $\mathrm{dP}<0.0$ (Significantly different from negative control group). $\mathrm{NC}$ : neutral control. NaCl and Vit $\mathrm{C}$ are negative and positive controls, respectively. $200+\mathrm{NaCl}$ group received K. pinnata extract $(200 \mathrm{mg} / \mathrm{kg}$ ) concurrently with $12 \% \mathrm{NaCl}$.

Table 2 Effects of Kalanchoe pinnata aqueous extract on leukocytes of mice

\begin{tabular}{|c|c|c|c|c|c|c|c|}
\hline Animal group & $\mathrm{WBCx} \mathbf{1 0}^{3} \mathrm{~mm}^{3}$ & Lymphpocytes & Percentage lymphocytes & Granulocytes & Percentage granulocyte & Monocytes & Percentage monocytes \\
\hline NC & $10.44 \pm 0.32$ & $7.55 \pm 0.12$ & $51.72 \pm 0.57$ & $2.65 \pm 0.09$ & $19.40 \pm 0.16$ & $1.44 \pm 0.13$ & $2.65 \pm 0.009$ \\
\hline $\mathrm{NaCl}$ & $9.25 \pm 0.19$ & $5.47 \pm 0.11^{* *}$ & $57.11 \pm 1.08$ & $2.32 \pm 0.15$ & $19.00 \pm 0.19$ & $1.52 \pm 0.11$ & $2.32 \pm 0.15$ \\
\hline 25 & $10.52 \pm 0.11$ & $5.82 \pm 0.04 * *$ & $65.42 \pm 1.19 *$ & $2.37 \pm 0.15$ & $19.02 \pm 0.22$ & $2.77 \pm 1.56$ & $2.37 \pm 0.15$ \\
\hline 50 & $10.69 \pm 0.18$ & $5.24 \pm 0.17 * *$ & $73.45 \pm 0.91 * *$ & $2.19 \pm 0.10$ & $19.05 \pm 0.32$ & $1.49 \pm 0.11$ & $2.19 \pm 0.10$ \\
\hline 100 & $10.61 \pm 0.99$ & $4.75 \pm 0.05^{* *}$ & $72.40 \pm 3.8 * *$ & $2.29 \pm 0.10$ & $18.74 \pm 0.28$ & $1.42 \pm 0.07$ & $2.29 \pm 0.12$ \\
\hline 200 & $10.71 \pm 0.18$ & $5.78 \pm 0.12^{* *}$ & $65.46 \pm 2.19 *$ & $2.31 \pm 0.09$ & $18.82 \pm 0.31$ & $1.65 \pm 0.10$ & $2.31 \pm 0.09$ \\
\hline $200+\mathrm{NaCl}$ & $11.29 \pm 0.32^{\mathrm{d}}$ & $5.41 \pm 0.19^{* *}$ & $70.44 \pm 1.78 * * \mathrm{c}$ & $2.53 \pm 0.14$ & $18.89 \pm 0.36$ & $1.71 \pm 0.08$ & $2.53 \pm 0.14$ \\
\hline Vit C & $11.04 \pm 0.19$ & $5.55 \pm 0.17 *$ & $73.12 \pm 1.99 * *$ & $2.20 \pm 0.06$ & $18.66 \pm 0.25$ & $1.53 \pm 0.09$ & $2.20 \pm 0.06$ \\
\hline
\end{tabular}

Each value represents the mean $\pm \mathrm{SEM}, \mathrm{n}=6 .{ }^{*} \mathrm{P}<0.01,{ }^{* *} \mathrm{P}<0.001$ (Significantly different from neutral control), $\mathrm{dP}<0.001$ (significantly different from negative control). $\mathrm{NC}$ : neutral control. NaCl and Vit $\mathrm{C}$ are negative and positive controls, respectively. $200+\mathrm{NaCl}$ group received $\mathrm{K}$. pinnata extract $(200 \mathrm{mg} / \mathrm{kg})$ concurrently with $12 \% \mathrm{NaCl}$ 
Table 3 Effects of Kalanchoe pinnata aqueous extract on biomarkers of fatigue in the blood

\begin{tabular}{|c|c|c|c|c|c|c|c|c|}
\hline Animal Group & NC & $\mathrm{NaCl}$ & 25 & 50 & 100 & 200 & $200+\mathrm{NaCl}$ & VitC \\
\hline Glycemia (mg/dL) & $123.50 \pm 9.7$ & $94.27 \pm 1.96$ & $90.89 \pm 2.87$ & $89.05 \pm 1.7$ & $84.62 \pm 1.2$ & $71.76 \pm 0.70 *$ & $95.23 \pm 1.35$ & $94.95 \pm 1.84$ \\
\hline CK-MB (U/L) & $2.87 \pm 0.24$ & $7.99 \pm 0.155^{* * *}$ & $3.013 \pm 0.14$ & $3.92 \pm 0.16$ & $4.60 \pm 0.10$ & $4.72 \pm 0.08$ & $2.9 \pm 0.23 a$ & $2.86 \pm 0.15$ \\
\hline Trygliceride (mg/dL) & $131.0 \pm 1.7$ & $147.28 \pm 5.3$ & $100.62 \pm 2.05^{* *}$ & $65.13 \pm 2.83^{* *}$ & $53.44 \pm 2.18^{* *}$ & $47.26 \pm 1.63^{* *}$ & $172.5 \pm 4.4^{*}$ & $147.21 \pm 3.7^{*}$ \\
\hline Urea $(\mathrm{mg} / \mathrm{dL})$ & $41.49 \pm 0.63$ & $34.29 \pm 0.83^{*}$ & $30.508 \pm 1.24^{*}$ & $23.22 \pm 0.83^{* *}$ & $23.31 \pm 1.56^{* *}$ & $19.96 \pm 0.63^{* * *}$ & $45.14 \pm 1.36$ & $26.02 \pm 1.02^{* *}$ \\
\hline Lactatemia $(\mathrm{mmol} / \mathrm{L})$ & $35.23 \pm 0.88$ & $26.63 \pm 0.59^{*}$ & $23.5 \pm 0.95^{* *}$ & $28.4 \pm 1.19 * *$ & $18.8 \pm 0.50^{* * *}$ & $18.52 \pm 0.43^{* *}$ & $36.03 \pm 1.16$ & $18.75 \pm 0.26^{* * *}$ \\
\hline
\end{tabular}

Each value represents the mean $\pm \mathrm{SEM}, n=6 .{ }^{*} \mathrm{P}<0.05,{ }^{* *} \mathrm{P}<0.001,{ }^{* * *} \mathrm{P}<0.0001$ (significantly different from the neutral control group), aP $<0.001$ (significantly different from NaCl group)

$\mathrm{NC}$ : neutral control. $\mathrm{NaCl}$ and Vit $\mathrm{C}$ are negative and positive controls, respectively. $200+\mathrm{NaCl}$ group received K. pinnata extract (200mg/kg) concurrently with $12 \% \mathrm{NaCl}$

Table 4 Effects of Kalanchoe pinnata aqueous extract on biochemical markers in heart muscle of mice

\begin{tabular}{|c|c|c|c|c|c|c|c|c|}
\hline Animal group & NC & $\mathrm{NaCl}$ & 25 & 50 & 100 & 200 & $200+\mathrm{NaCl}$ & Vit C \\
\hline $\operatorname{MDA}(\mu \mathrm{mol} / \mathrm{g})$ & $24.10 \pm 1.72$ & $37.45 \pm 1.46^{*}$ & $28.71 \pm 3.63$ & $27.82 \pm 1.37$ & $26.04 \pm 1.48$ & $25.32 \pm 1.00$ & $24.44 \pm 1.89 a$ & $24.05 \pm 1.69$ \\
\hline $\mathrm{GPx}(\mu \mathrm{mol} / \mathrm{mg}$ protein $)$ & $0.75 \pm 0.04$ & $0.54 \pm 0.07$ & $0.64 \pm 0.14$ & $0.73 \pm 0.09$ & $0.74 \pm 0.05$ & $0.81 \pm 0.10$ & $0.66 \pm 0.11$ & $0.81 \pm 0.08$ \\
\hline Glyco (mg/g) & $1.15 \pm 0.05$ & $1.07 \pm 0.03$ & $1.03 \pm 0.27$ & $0.81 \pm 0.19$ & $0.56 \pm 0.07^{* *}$ & $0.57 \pm 0.08^{* *}$ & $0.73 \pm 0.09 * \mathrm{a}$ & $0.48 \pm 0.08^{* *}$ \\
\hline CK-MB $(\mu \mathrm{mol} / \mathrm{g})$ & $6.07 \pm 0.8$ & $9.28 \pm 0.37^{*}$ & $5.33 \pm 0.16$ & $5.14 \pm 0.30$ & $5.72 \pm 0.38$ & $6.40 \pm 0.75$ & $5.74 \pm 0.68^{a}$ & $5.92 \pm 0.98$ \\
\hline
\end{tabular}

Each value represents the mean $\pm \mathrm{SEM}, \mathrm{n}=6 .{ }^{*} \mathrm{P}<0.001$ (significantly different from neutral control); ${ }^{\mathrm{P}}<0.001$ (significantly different from negative control). $\mathrm{NC}$ :

Neutral control. $\mathrm{NaCl}$ and Vit $\mathrm{C}$ are negative and positive controls, respectively. $200+\mathrm{NaCl}$ group received K. pinnata extract $(200 \mathrm{mg} / \mathrm{kg})$ concurrently with $12 \% \mathrm{NaCl}$

Table 5 Effects of Kalanchoe pinnata aqueous extract on biochemical markers in gastrocnemius muscle of mice

\begin{tabular}{|c|c|c|c|c|c|c|c|c|}
\hline Animal group & NC & $\mathrm{NaCl}$ & 25 & 50 & 100 & 200 & $200+\mathrm{NaCl}$ & Vit C \\
\hline $\operatorname{MDA}(\mu \mathrm{mol} / \mathrm{g})$ & $19.93 \pm 0.73$ & $38.83 \pm 0.72^{* * * *}$ & $35.84 \pm 0.9^{* * * *}$ & $26.96 \pm 1.22^{* * *}$ & $22.2 \pm 1.68$ & $22.58 \pm 2.82$ & $21.48 \pm 1.55^{b}$ & $18.86 \pm 0.70$ \\
\hline $\mathrm{GPx}(\mu \mathrm{mol} / \mathrm{mg}$ protein $)$ & $0.79 \pm 0.02$ & $0.45 \pm 0.07^{* *}$ & $0.72 \pm 0.14$ & $0.77 \pm 0.10$ & $0.77 \pm 0.08$ & $0.83 \pm 0.05$ & $0.95 \pm 0.05^{\mathrm{a}}$ & $0.88 \pm 0.06$ \\
\hline Glyco (mg/g) & $1.08 \pm 0.03$ & $1.78 \pm 0.16^{*}$ & $1.41 \pm 0.30$ & $1.41 \pm 0.32$ & $0.57 \pm 0.09 * *$ & $0.55 \pm 0.08^{* * *}$ & $0.66 \pm 0.10^{\mathrm{a}}$ & $0.48 \pm 0.08^{* * *}$ \\
\hline
\end{tabular}

Each value represents the mean $\pm \mathrm{SEM}, n=6 .{ }^{*} \mathrm{P}<0.05,{ }^{* *} \mathrm{P}<0.01^{* * *} \mathrm{P}<0.001,{ }^{* * * *} \mathrm{P}<0.0001$ (significantly different from the neutral control group); $\mathrm{P}<0.01$, ${ }^{\mathrm{P}} \mathrm{P}<0.0001$ (significantly different from the negative control group). 


\section{Discussion}

This study aimed at evaluating the effects of the aqueous leaf extract of $K$. pinnata on the haematological and fatigue status of mice performing in the free-swimming endurance test. The free swimming endurance test represents a valid animal model for screening anti-fatigue potency of bioactive compounds [17]. A good haematological profile with normal indices ranges is definitely beneficial in the performance of athletes. A drop of the level of haemoglobin and/or red blood cells would be harmful to individuals during a erobic race like endurance swimming. There were controversial findings in this study as the RBC in the treatment groups $50 \mathrm{mg} / \mathrm{kg}$ and $200 \mathrm{mg} / \mathrm{kg}+\mathrm{NaCl}$ were significantly lower than the neutral control group meanwhile no change was observed with the lone administration of the extract at 25,100 and $200 \mathrm{mg} / \mathrm{kg}$ of body weight/day. Platelets are known to prevent excessive posttraumatic blood loss at sites of vascular injury by forming a platelet plug [18]. The extract at the highest dose of $200 \mathrm{mg} / \mathrm{kg} /$ day was able to prevent the drop of platelets caused by the lone administration of $\mathrm{NaCl}$, this could be beneficial in the prevention of haemorrhage. The extract did not lower the Haemoglobin level. Haemoglobin is the main component of erythrocytes whose main function is to serve as the carrier for oxygen and carbon dioxide. Hb also plays a role in the maintenance of the body fluid's acid/alkaline balance [19]. Therefore, it can directly affect energy metabolism, body function, and exercise ability, the loading capacity of the exercise and consequently fatigue [20]. Hb normally is one of the indicators that reflect the degree of recovery from fatigue after exercise, and higher levels of $\mathrm{Hb}$ can improve exercise ability [21]; it is rather advantageous that no noxious effect of the plant extract was observed on this blood index. Our results are in line with the findings by Okwari et al. [22]

$12 \% \mathrm{NaCl}$ was administered with the purpose to create a permanent electrolytic imbalance in the internal environment during the experiment and prompt the heart of treated mice to cardiovascular impairments such as myocardial stiffness, hypertension or any other cardiovascular condition that could harden the work of the heart $[12,13,14]$; in the same line it has been reported by Dobrian et al. [12] that high $\mathrm{NaCl}$ diet can increase the oxidative stress in rodents, all of the above suggesting a possible impairment of the mice performances. Surprisingly, we observed a significantly greater endurance from the treated mice. On the other hand, it has been reported that too much sodium is harmful to both heart health/efficiency $[13,14,23]$, thus the fact that the extract prevents the harmful effect of $\mathrm{NaCl}$ is without any doubt very advantageous. Nevertheless, administration of the extract during a sub-chronic to chronic experimentation will definitely offer better chances to improve the healthy condition of the heart and therefore allow the heart to perform better during endurance swimming: that should be a strong contribution to the delay of the onset of fatigue in performing mice. Thus future investigations should be carried out for a 4-week experimental period. The results showed that the swimming time to exhaustion was significantly longer for negative $(\mathrm{NaCl})$ and positive (Vit $\mathrm{C}$ ) than the neutral control group. Vit $\mathrm{C}$ has been proven to act as an anti-oxidant and anti-fatigue agent [24]. Once more, while the findings for Vit $\mathrm{C}$ are in order, it is rather strange that $\mathrm{NaCl}$ administered mice were similarly tolerant to exercise.

A non significant increase of the swimming duration was observed in the groups administered with 50 and $100 \mathrm{mg} / \mathrm{kg}$ of body weight/day of the plant extract. Although this observation does not clearly argue in favour of the anti-fatigue activity of the extract, the biochemical analyses of the effects of $K$. pinnata on the levels of BUN and BLA showed a reduction of these biomarkers of fatigue by the plant extract. The latter observations are rather favourable to a potential anti-fatigue activity of the extract, since it has been reported that such decreases are indicative of anti-fatigue properties $[15,25,26]$. In fact, BUN levels and the degree of exercise tolerance is well known [26]. The less adapted or tolerant the body is to prolonged exercise, the more significant the rise in BUN levels following protracted exercise [27]. The results therefore suggest that, treatment with Kalanchoe pinnata aqueous extract for 14 days can contribute to fatigue retardation by reducing protein catabolism directly in the tissues and blood urea indirectly during exercise. With the accumulation of blood lactate, blood and muscle tissue $\mathrm{pH}$ reduces, a condition which is harmful to some vital organs and which also causes fatigue [28]. Blood lactate levels are therefore representative of the degree of post exercise fatigue and the condition of recovery [29]. Anti-fatigue agents have been shown to effectively work by delaying lactate accumulation either by reducing the glycolytic process or by increasing the rate of removal of blood lactate [30]. The leaf extract of Kalanchoe pinnata could effectively delay the onset of fatigue through one or both of these mechanisms. However, the treatment duration of two weeks might have been short for animal to acquire significant tolerance to endurance exercise, expressed by significant delay of the exhaustion times.

On the other hand, the reduction of blood glucose and triglycerides by the extract, as well as the prevention by $200 \mathrm{mg} / \mathrm{kg}$ of extract of the increase of CK-MB caused by $\mathrm{NaCl}$ argue in favour of a proper utilization of those energy sources by the animals; as well as a cardioprotective activity of the plant extract. More specifically eventual cardiac infarctus could be prevented. ${ }^{9}$ These beneficial effects of the extract might directly improve the ability of the mice to perform, thus limiting their move towards fatigue. However, the reduced blood glucose might be interpreted also as the fact that the extract does not stimulate the breakdown of liver/muscle glycogen to glucose, while glucose is being used 
adequately. In that case instead it might not always be advantageous, since high levels of glucose need to be metabolized to improve on the performance and tolerance to endurance exercise [31]. Heart and gastrocnemius muscle glycogen reserves constitute reliable determinants of fatigue on which endurance capacity relies [32]. Following the freeswimming endurance test, Kalanchoe pinnata extract-treated mice at 100 and $200 \mathrm{mg} / \mathrm{kg}$ maintained significantly lower concentrations of gastrocnemius muscle and heart glycogen reserves, compared with the controls. The importance of muscle glycogen levels in endurance exercise has been demonstrated and it is suggested that depletion of muscle glycogen is an important factor in fatigue and exhaustion [26]. However, there is evidence that energy provision for intense prolonged aerobic muscular work relies more on fat utilization [33].

In this study, serum triglyceride levels were significantly lowered in all extract treated groups, compared with the controls, meaning that $K$. pinnata extract could have some properties to delay the onset of vascular diseases, such as atherosclerosis due to fat deposit. The plant extract caused a decrease of the level glucose in the gastrocnemius and once more this might not appear, at the first glance, as a beneficial activity of the plant extract for performance and tolerance to fatigue. However, the associated significant drop in serum triglyceride concentrations and muscle glucose level after endurance exercise suggest that $K$. pinnata extract preferentially promoted the utilization of fat during prolonged exercise, a glycogen-sparing mechanism that delays the onset of fatigue [34]. There is experimental evidence that endurance can be improved by increasing the availability of fatty acids while slowing glycogen depletion [35].

Intense physical exercise also causes oxidative stress in the body due to excessive generation of oxygen-derived free radicals. Some evidence indicates that reactive oxygen species (ROS) are responsible for exercise induced protein oxidation and contribute strongly to muscle fatigue [36,37]. Malone dialdehyde (MDA) is one of the degradation products in the lipid peroxidation process [38]. $12 \% \mathrm{NaCl}$ caused significant increase of MDA in both the heart and the gastrocnemius, but no significant variation was observed in the groups receiving solely the extract, especially at 100 and $200 \mathrm{mg} / \mathrm{kg} /$ day. The highest dose of extract prevented this MDA increase, so confirming the antioxidant activity of the extract [39] and in the meantime an anti-fatigue property. Antioxidant properties have been reported as strong contributors to anti-fatigue activities $[15,40]$. Glutathione peroxidase, another biomarker of oxidative stress. decreased non significantly in the heart and significantly in the gastrocnemius, as compared to the neutral control. The significant decrease was in turn significantly prevented by the extract $(200 \mathrm{mg} / \mathrm{kg} /$ day $)$ concurrently administered. Our results indicated that the anti-fatigue effect of $K$. pinnata extract possibly occurs through protection of corpuscular membranes by preventing lipid oxidation via modifying activities of several enzymes. These results are in accordance with the findings of Wang et al. [41], which demonstrated similar effects of ginseng polysaccharides on MDA and GPx levels. However the gastrocnemius MDA instead increased at lower doses of $K$. pinnata administered solely. These results respond to the notion that antioxidants can paradoxically become prooxidant when administered at totally different doses [42]. The results obtained here may therefore reflect a dual effect of the extract, as the doses vary, with excessively massive import of a high concentration of one or more potent antioxidant components of the extract at the dose of $200 \mathrm{mg} / \mathrm{kg}$.

Overall, the biochemical profile of mice administered with the plant extract alone or concurrently with $12 \% \mathrm{NaCl}$ displaying the anti-fatigue potential of the extract, which is not clearly observable on the swimming time records, we believe that the sample size (six/group) and the duration of treatment (14days) could have been limitations for the clear expression of the properties of the extract. Therefore, future studies should be carried out for 28 days and with larger sample size, to confirm the current findings.

\section{Conclusion}

Kalanchoe pinnata leaf aqueous extract possesses anti-fatigue properties. Although the increase of the swimming duration was not significant, compared to neutral control, findings from biochemical analyses have shown delay of the accumulation of blood lactate and blood urea nitrogen, increase of the use of triglycerides and utilization of stored glycogen. All of the above added to the antioxidant activity of the extract support the hypothesis that K. pinnata could be used to delay the onset of exercise induced fatigue.

\section{Compliance with ethical standards}

\section{Acknowledgments}

The authors are very grateful to Professor Halle Ekane Edie Gregory for the provision of some laboratory facilities 


\section{Authors' Contributions}

This work was carried out in collaboration between all authors. Authors OSMB, GST Conceived and designed the experiments. Author OSMB wrote the manuscript. Author OPM carried out the major part of the bench work and performed the statistical analysis. Author MPM prepared the plant extract and participated in statistical analysis. Author TD made provision of Laboratory facilities. All authors read and approved the final manuscript.

\section{FUNDING}

This research did not receive any specific grant from funding agencies in the public, commercial, or not-for-profit sectors

\section{Disclosure of conflict of interest}

Authors have declared that no competing interests exist.

\section{Statement of ethical approval}

The experimental protocol was approved by the University of Buea Institutional Animal Care and Use Committee (2016/01/UB/IACUC/BTU/FS) and animals were carefully handled all through the experiment, following international guidelines [11].

\section{References}

[1] Bassuk SS, Manson Jo AE. Epidemiological evidence for the role of physical activity in reducing riskof type 2 diabetes and cardiovascular disease. J Appl Physiol. 2005; 99: 1193-204.

[2] Moxnes JF Sandbakk $\emptyset$. The kinetics of lactate production and removal during whole-body exercise. Theor Biol Med Model. 2012; 9: 7-20.

[3] Cottin F, Papelier Y, Escourrou P. Effects of exercise load and breathing frequency on heart rate and blood pressure variability during dynamic exercise. Int J Sports Med. 1999; 20(4): 232-8.

[4] Lawan A, Noraniza MA, Rasedee A, Bashir A. Effect of strenuous sub-maximal race on heart rates of endurance horses. Malays J Vet Res. 2012; 3(1): 29-32.

[5] Alves JC, Santos AM. Physiological, haematological and biochemical shifts in police working dogs during a riot control exercise. Comp Exerc Physiol. 2016; 12(4): 193-8.

[6] Lawan A, Noraniza MA, Rasedee ABA. Effects of Race Distance on Physical, Hematological and Biochemical Parameters of Endurance Horses. Am J Anim Vet Sci. 2010; 5(4): 244-8.

[7] Hodgson DR, Rose RJ. The athletic horse: principles and practice of equine sports medicine. Philadelphia. Saunders. 1994.

[8] Milad R, El-Ahmady S, Singab AN. Genus Kalanchoe (Crassulaceae): A Review of its Ethnomedicinal, Botanical, Chemical and Pharmacological Properties. European J Med Plants. 2014; 4(1): 86-104.

[9] Bopda OSM, Koumtouzi NNC, Bilanda D, Dzeufiet DPD, Keambou CT, Dimo T. Kalanchoe pinnata aqueous extract safety and potential cardioprotective effects in isoprenaline treated rats. J Phytopharmacol. 2018; 7(5): 404-11.

[10] Yemitan OK, Salahdeen HM. Neurosedative and muscle relaxant activities of aqueous extract of Bryophyllum pinnatum. Fitoterapia. 2005; 76(2): 187-93.

[11] Bankowski Z. CIOMS. International guiding principles for biomedical research involving animals. 1985. Accessed 03 January. 2013.

[12] Dobrian AD, Schriver SD, Lynch T, Prewitt RL. Effect of salt on hypertension and oxidative stress in a rat model of diet-induced obesity. Am J Physiol Renal Physiol. 2003; 285: F619-F628.

[13] Eckel RH, Jakicic JM, Ard JD, De Jesus JM, Miller NH, Hubbard VS, Lee I-M, Lichtenstein AH, Loria CM, Millen BE, Nonas CA, Sacks FM, Smith SC, Svetkey LP, Wadden TA, Yanovski SZ. AHA/ACC Guideline on Lifestyle Management to Reduce Cardiovascular Risk. A Report of the American College of Cardiology/American Heart Association Task Force on Practice Guidelines. Circulation. 2014; 129[2]: S76-S99.

[14] Whelton PK, Appel LJ, Sacco RL, Anderson CAM, Antman EM, Campbell N, Dunbar SB, Frohlich ED, Hall JE, Jessup M, Labarthe DR, MacGregor GA, Sacks Frank M, Stamler Jeremiah, Vafiadis Dorothea K, Van Horn LV. Sodium, 
Blood Pressure, and Cardiovascular Disease: Further Evidence Supporting the American Heart Association Sodium Reduction Recommendations. Circulation. 2012; 126: 2880-9.

[15] Lamou B, Taiwe GS, Hamadou A, Houlray AJ, Atour MM, Tan PV. Antioxidant and Antifatigue Properties of the Aqueous Extract of Moringa oleifera in Rats Subjected to Forced Swimming Endurance Test. Oxid Med Cell Longev. 2016; 9.

[16] Chun Y, Yin ZD. Glycogen assay for diagnosis of female genital Chlamydia trachomatis infection. J Clin Microbiol. 1998; 36(4): 1081-2.

[17] Hao G, Zhang C, Cao W, Hao J. Effects of intragastric administration of five oyster components on endurance exercise performance in mice. Pharm biol. 2014; 52(6): 723-8.

[18] De Meye SF. Platelet granules in vascular integrity. Blood. 2017; 129: 1573-4.

[19] Nikinmaa, MIKKO. Oxygen and carbon dioxide transport in vertebrate erythrocytes: an evolutionary change in the role of membrane transport. J Exper Biol. 1997; 200(2): 369-80.

[20] Gao SJ, Wu D. Research of various dosage carnosine affecting on antifatigue of mobility for rats. J Guangzhou Sport Univers. 2008; 28: 90-2.

[21] Kamakura M, Mitani N, Fukuda T, Fukushima M. Antifatigue effect of fresh royal jelly in mice. J Nutr Sci Vitaminol (Tokyo). 2001; 47(6): 394-401.

[22] Okwari 00, Emerole CG, Dasofunjo K, Ezugwu HC, Obi J. Haematological profile of rats administered with aqueous leaf extract of Moringa oleifera following thermooxidixed palm oil diet induced toxicity. IOSR J Pharm Biol Sci. 2014; 9(1): 41-5.

[23] Strazzullo P, D'Elia L, Kandala NB, Cappuccio FP. Salt intake, stroke, and cardiovascular disease: meta-analysis of prospective studies. BMJ. 2009; 339: b4567.

[24] Maret GT, Jan FS. Vitamins C and E: Beneficial effects from a mechanistic perspective. Free Radic Biol Med. 2011; 51(5): 1000-13.

[25] Evans DA, Subramoniam A, Rajasekharan S, Pushpan- gadan P. Effect of Trichopus zeylanicus leaf extract on the energy Oxidative Medicine and Cellular Longevity metabolism in mice during exercise and at rest. Indian J Pharmacol. 2002; 34(1): 32-7.

[26] Shang HP, Cao SH, Wang JH, Zheng H, Putheti R. Glabridin from Chinese herb licorice inhibits fatigue in mice. Afr J Tradit Complement Altern Med. 2009; 7(1): 17-23.

[27] Zhang Y, Yao X, Bao B, Zhang Y. Antifatigue activity of a triterpenoid-rich extract from Chinese bamboo shavings (Caulis bamfusae in taeniam). Phytother res. 2006; 20(10): 872-6.

[28] Kim NH, Moon PD, Pak SC, Kim HM, Jeong HJ. Antifatigue effect of Zizania caudiflora (Turczaninow) Nakai. Am J Chin Med (Gard City N Y). 2012; 40(01): 111-20.

[29] Yu B, Lu ZX, Bie XM, Lu FX, Huang XQ. Scavenging and anti-fatigue activity of fermented defatted soybean peptides. Eur Food Res Technol. 2008; 226(3): 415-21.

[30] Evans DA, Subramoniam A, Rajasekharan S, Pushpangadan P. Effect of Trichopus zeylanicus leaf extract on the energy metabolism in mice during exercise and at rest. Indian J Pharmacol. 2002; 34(1): 32-7.

[31] Andrew RC. Plasma Glucose Metabolism during Exercise in Humans. Sports Med. 1991; 11(2): $102-24$.

[32] Dohm GL, Tapscott EB, Barakat HA, Kasperek GJ. Influence of fasting on glycogen depletion in rats during exercise. J Appl Physiol Respir Environ Exerc Physiol. 1983; 55(3): 830-3.

[33] Jones NL, Havel RJ. Metabolism of free fatty acids and chylomicron triglycerides during exercise in rats. American Journal of Physiology-Legacy Content. 1967; 213(4): 824-8.

[34] Guezennec CY, Pesquies PC. Biochemical basis for physical exercise fatigue. High Altitude Deterioration. 1985; 19: 79-89.

[35] Favier RJ, Koubi HE. Metabolic and structural adaptations to exercise in chronic intermittent fasted rats. Am J Physiol Regul Integr Comp Physiol. 1988; 254(6): R877-R84.

[36] Powers SK, Hamilton K. Antioxidants and exercise. Clin Sports Med. 1999; 18(3): 525-36. 
[37] Powers SK, Deruisseau KC, Quindry J, Hamilton KL. Dietary antioxidants and exercise. J sports sci. 2004; 22(1): 81-94.

[38] Ding JF, Li YY, Xu JJ, Su XR, Gao X, Yue FP. Study on effect of jellyfish collagen hydrolysate on antifatigue and antioxidation. Food Hydrocoll. 2011; 25(5): 1350-3.

[39] Bopda OSM, Longo F, Bella NT, Edzah PMO, Taïwe GS, Bilanda DC, Tom ENL, Kamtchouing P, Dimo T. Antihypertensive activities of the aqueous extract of Kalanchoe pinnata (Crassulaceae) in high salt-loaded rats. Journal of Ethnopharmacology. 2014; 153: 400-7.

[40] Fan L, Zhai F, Shi D, Fan L, Zhai F, Shi D, Qiao X, Fu X, Li H. Evaluation of antioxidant properties and antifatigue effect of green tea polyphenols. Sci Res Essays. 2011; 6(13): 2624-9.

[41] Wang L, Zhang HL, Lu R, Zhou YJ, Ma R, Lv JQ, Yao Z. The decapeptide CMS001 enhances swimming endurance in mice. Peptides. 2008; 29(7): 1176-82.

[42] Wilbur KM. The thiobarbituric acid reagent as a test for the oxidation of unsaturated fatty acids by various agents. Archs Biochem Biophys. 1949; 24: 305-13. 